\title{
Investigation of the TIG Welding Process for Joining AA6082 Alloy Using Grey Relational Analysis
}

\author{
G. Sathish Kumar, ${ }^{1}$ M. Ramesh, ${ }^{2}$ S. Dinesh, ${ }^{1}$ Prabhu Paramasivam ${ }^{\mathbb{D}},{ }^{3}$ and N. Parthipan ${ }^{4}$ \\ ${ }^{1}$ Department of Mechanical Engineering, K. Ramakrishnan College of Technology (Autonomous), Kariyamanikam Road, \\ Samayapuram, Tiruchirappalli, Tamilnadu 621112, India \\ ${ }^{2}$ Department of Mechanical Engineering, K. Ramakrishnan College of Engineering (Autonomous), Kariyamanikam Road, \\ Samayapuram, Tiruchirappalli, Tamilnadu 621112, India \\ ${ }^{3}$ Department of Mechanical Engineering, College of Engineering and Technology, Mettu University, 318, Metu, Ethiopia \\ ${ }^{4}$ Department of Mechanical Engineering, M.Kumarasamy College of Engineering, Thalavapalayam, Karur 639113, India
}

Correspondence should be addressed to Prabhu Paramasivam; drprabhu@meu.edu.et

Received 9 November 2021; Revised 23 December 2021; Accepted 3 January 2022; Published 25 January 2022

Academic Editor: Fuat Kara

Copyright (c) 2022 G. Sathish Kumar et al. This is an open access article distributed under the Creative Commons Attribution License, which permits unrestricted use, distribution, and reproduction in any medium, provided the original work is properly cited.

\begin{abstract}
The goal of this project is to find optimization parameters in the TIG weld bead. To ensure the success of this research project, a semiautomatic TIG was developed. Samples are made in a single bead on top of a substrate (base metal) in a horizontal position. Aluminum 6082 is used as the substrate, and AA5356 filler wire with a diameter of $2.4 \mathrm{~mm}$ is used as the filler wire. This research project employs argon as the shielding gas. Welding current (A), travel speed $(\mathrm{mm} / \mathrm{min})$, and gas flow rate (lit/min) have all been identified as influencing parameters for welding. The Taguchi orthogonal array L9 (Minitab 19) was used to calculate the amount of runoff and analyze the samples. Tensile and hardness tests were performed on the welded samples. According to the test results, as the current value increases, the tensile strength and the hardness values decrease. As a result of this experiment, it is possible to conclude based on grey relational analysis that the best parameters for welding $\mathrm{Al} 6082$ alloy are $150 \mathrm{~A}$ of welding current, $200 \mathrm{~mm} / \mathrm{min}$ of travel speed, and a gas flow rate of 14 lit/min.
\end{abstract}

\section{Introduction}

The process that facilitates the joining of different materials such as metals, plastics, and alloys through controlled heat under pressure or nonpressure conditions is called welding. On application of controlled heat at the interface, the materials tend to melt initially, and a permanent joint is produced after solidifying the melted material at the interface [1-4]. The joint may be formed by using flux or filler material depending upon the type of material selected and application of the joint. The GTAW or TIG welding process produces welds with an electrode made of tungsten as shown in Figure 1. The inert gases are widely used to cover the area welded from the atmosphere (helium, argon, or a combination of helium and argon) [5-7]. For proper welding, filler metal can also be fed manually. GTAW, also known as the TIG welding process, was invented during World War II. The joining of harder-to-join materials, such as aluminum and magnesium, has become likely with the advancement of the TIG welding process. Welding thick aluminum alloy plates can be accomplished using a variety of techniques [8-11]. However, arc welding, such as GMAW and TIG welding, is a more cost-effective option due to lower energy consumption and greater flexibility [12]. The formation of pore defects during fusion welding is a significant issue in welding thick plates of $\mathrm{Al}$ alloys [13].

Typically, the strength of the TIG welded joint of AA 6082 has been higher than the joint obtained with MIG welding. The tensile strength was higher due to the better equal-sized grain structure due to the narrow spacing arms. Also, the travel speed of the electrode directly influences the phenomenon of softening in the area of the weld. The hardness at the weld has been increased through aging under $0^{\circ} \mathrm{C}$ [14]. With two different filler materials, AA 4043 and AA 4047, a double side V butt weld joint was created. When the current increases from $80 \mathrm{Amp}$ to $120 \mathrm{Amp}$, the tensile 


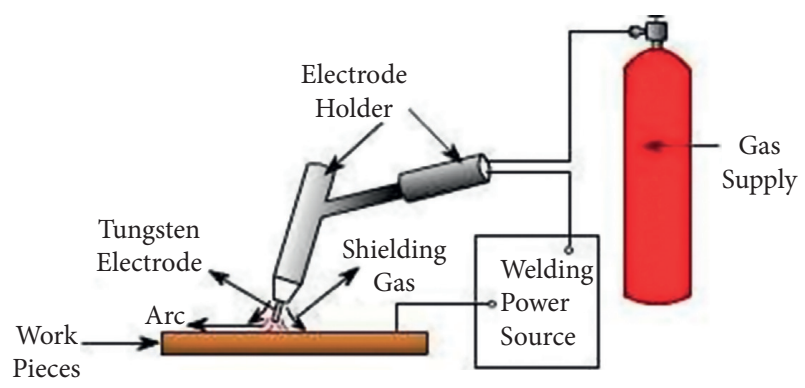

FIgURE 1: Welding system of TIG.

strength increases by $4.5 \%$ on average while using argon as shielding gas. When AA 4043 is used instead of AA 4047, the results are better. The geometry of the weld zone, such as the front width and front height, determines TIG weld superiority $[15,16]$. This is because the weld zone geometry acts as a vital part in defining the mechanical properties of the weld zone. Thus, selecting appropriate process parameters for welding is critical to achieving an ideal weld zone geometry [17]. Because of the melting of the base material during welding, the microstructure and mechanical properties of the Al alloy will change [18]. TIG welding is preferred for aluminum alloys because it spreads out from the weld pool more than other processes. Various methods have been adopted to improve the refinement of grain boundaries in the region of weld [19]. In casting, inoculation for refining the fusion zone is successful, but not in welding. The surface nucleation technique was also not widely used due to the complicated setups and procedures required. Heat input was selected as the investigational system because it allows one to examine the effect of many TIG welding process parameters such as weld speed, weld current, and voltage directly by varying the heat input. As a result, different heat input values associated with changes in welding parameters accompanied some metallurgical disparities [20]. Heat is a significant factor in deciding joint mechanical performance during TIG welding. It was discovered that increasing the heat input reduces joint strength based on the formation of a broad heat-affected zone and coarsening of precipitation size. Many researchers have worked on parameter selection to obtain the best weld pool surface using a fully automated TIG system [21, 22]. However, obtaining the optimal surface properties of the welded joint is something that has yet to be fully discovered. As a result, this research project will concentrate on parameter estimation to improve performance, surface integrity, and reinforcing the body of the welded joint by using a semiautomatic TIG setup. Semiautomatic TIG welding is easy to install and can be personalized using standard TIG welding equipment.

According to the existing literature, the welding of aluminum presents a significant challenge. Although friction stir welding and laser welding are widely used for aluminum grades, they appear to be expensive. As a result, for economic gain, TIG welding is suggested in this research project. Again, the internal consistency of welding is determined by its control over processing parameters. As a result, the parameters must be adjusted appropriately in order to achieve sound weld output. So, in this work, grey relational analysis is used to determine the operating parameters, and welding is done with that DOE. Welding was also done from both sides to increase strength.

\section{Materials, Methods, and Experimental Setup}

The aluminum alloy 6082-T6 is part of the $6 \mathrm{xxx}$ series. Magnesium and silicon are the two main alloying elements. It has good workability in the annealed state. A Fronius rectifier with a current range of 10-180 A and a voltage range of up to $230 \mathrm{~V}$, depending on the current setting, was used. Because aluminum is a soft material, it was simple to cut with a bench shear for rough cuts. A total of 18 of these pieces were cut, with a pair forming a weld, that is, 9 different pairs of weld joints were required because each of the 3 configurations considered here contributed to 3 different pairs, requiring 9 different pairs of weld joints. AA5356 filler wire with a diameter of $2.4 \mathrm{~mm}$ is used as the filler wire. Figure 2 shows the workpieces after edge preparation and the welded joint. Table 1 provides the chemical composition of the material to be welded.

Tensile specimens were taken perpendicular to the weld direction. Tensile tests were carried out by ASTM E8 as shown in Figure 3 (tensile testing of metallic materials at room temperature). Tensile testing was performed at a rate of $8 \mathrm{~mm} / \mathrm{min}$. The specimens were tested on the FIE UTE-60 universal testing machine, an electronic type, hydraulically controlled digital tensile testing machine with a capacity of $400 \mathrm{KN}$. The term "microhardness tests" usually refers to static indentation with loads not exceeding $1 \mathrm{Kgf}$. In general, the surface about to be tested needs a metallographic finish; a relatively small load requires a higher surface finish. The microhardness testing procedure is similar to the standard Vickers hardness testing procedure. Vickers hardness measurements were made from across HAZ and weld metal.

2.1. Grey Relational Analysis (GRA). GRA is the most broadly used method of grey theory and was established by Prof Deng Julong. It can solve incomplete data problems and problems that do not have data with at most correctness. The wide range of applications includes analysis of critical parameters, optimizing parameters for selected processes with multiple objectives, and selecting projects. The steps in GRA are preprocessing, location of GRC, and calculation of GRG. The preprocessing becomes essential when the problem is to be analyzed in scattered over an ample space. To produce equivalent results, normalizing, scaling, and polarizing the raw data are done. Initially, the original and comparative data series was referred to as " $A_{0}$ " and " $A_{i}$ " "respectively. Furthermore, the data are scaled from 0 to 1 . Depending on the situation, the data are normalized using (1) and (2).

For the "larger the better" condition,

$$
A_{i}(k)=\frac{A_{i}(k)-\min \left(A_{i}^{0}(k)\right)}{\max \left(A_{i}^{0}(k)\right)-\min \left(A_{i}^{0}(k)\right)} .
$$

For the "smaller the better" condition, 

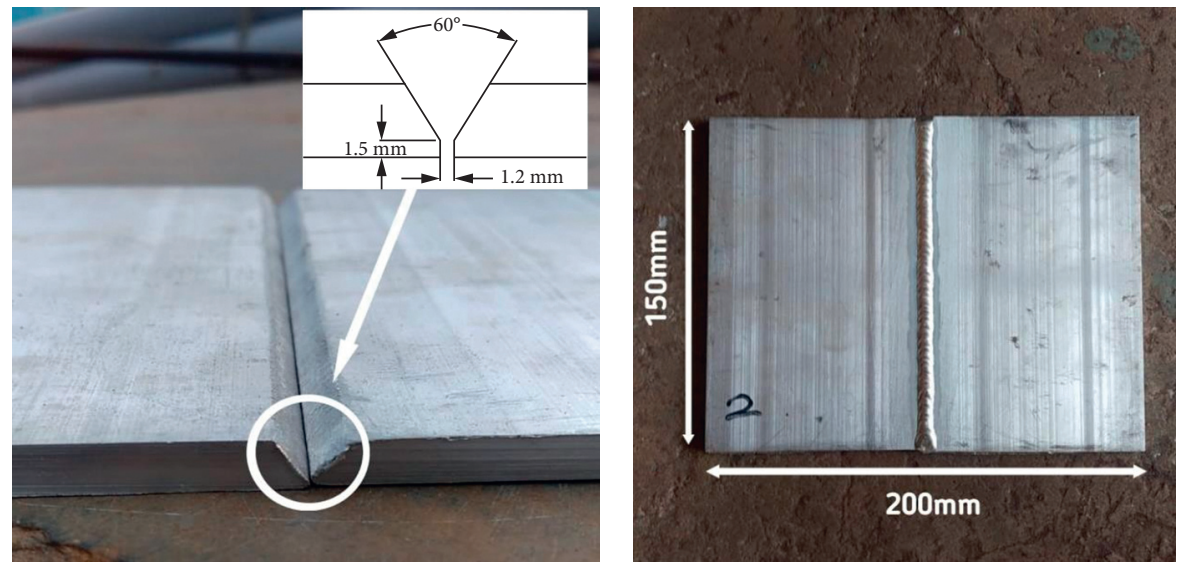

Figure 2: Weld samples.

TABle 1: Chemical composition of aluminum alloy 6082-T6.

\begin{tabular}{lc}
\hline Components & Percentage (\%) \\
\hline $\mathrm{Si}$ & 0.62 \\
$\mathrm{Mg}$ & 1.1 \\
$\mathrm{Fe}(\max )$ & 0.45 \\
$\mathrm{Cu}(\max )$ & 0.1 \\
$\mathrm{Mn}$ & 1 \\
$\mathrm{Cr}(\max )$ & 0.29 \\
$\mathrm{Zn}(\max )$ & 0.3 \\
$\mathrm{Ti}(\max )$ & 0.12 \\
$\mathrm{Al}$ & Balance \\
\hline
\end{tabular}

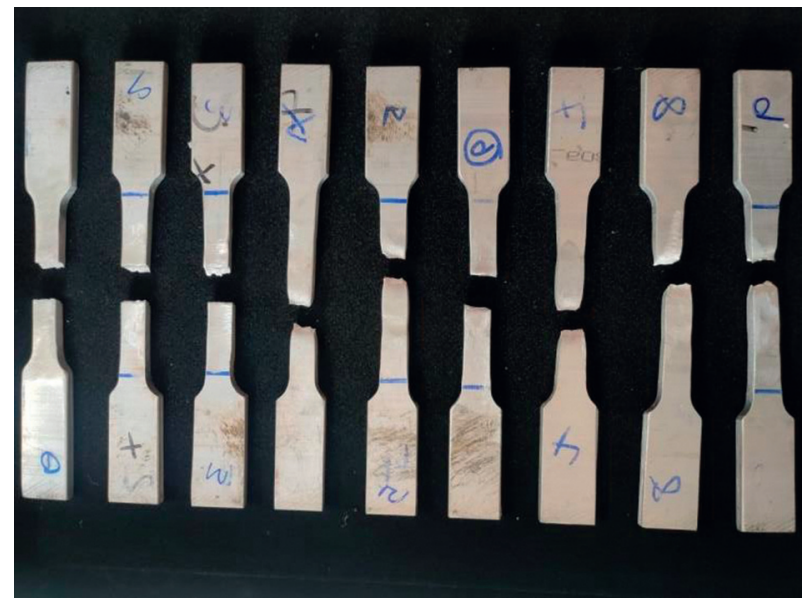

Figure 3: Tensile test specimens as per ASTM E8 standard.

$$
A_{i}(k)=\frac{\max \left(A_{i}(k)\right)-\left(A_{i}(k)\right)}{\max \left(A_{i}^{0}(k)\right)-\min \left(A_{i}^{0}(k)\right)},
$$

where " $i$ " can range from 1 to $a$ and $k$ can range from 1 to $b$. The number of experimental data points collected is denoted by " $a$," and the number of parameters is denoted by $b . A_{i}^{0}(k)$ is the original data framework, $A_{i}^{*}(k)$ is the data system after data preprocessing, and $\min \left(A_{i}^{0}(k)\right)$ and $\max \left(A_{i}^{0}(k)\right)$ are the smallest and largest values $A_{i}^{0}(k)$, respectively.

The deviation sequence is the difference between the maximum normalized value of the corresponding quality characteristic and the normalized value of the corresponding experiment. The grey relational coefficient is used after preprocessing to connect the model, and the normalized values show the formula for calculating GRC:

$$
\xi_{i}(k)=\frac{\Delta \min -\zeta \Delta \max }{\Delta_{i, o}(k)+\zeta \Delta \max }
$$

where the grey relational coefficient is represented by $\xi_{i}(k)$ $(0-1)$. The identity coefficient $(\zeta)$, which is 0.5 , serves as a minor distinguishing feature. The sequence's min and $\max$ $(\Delta \min$ and $\Delta \max )$ values are the least and most prominent $(0$ and 1). The original system of values is $A_{i}^{0}(k)$, and the system of values after data preprocessing is $A_{i}^{*}(k)$.

After receiving a grey relational coefficient, the grey relational grade is calculated by taking the average of the grey relational codes. The GRG will be ranked from most stringent to least stringent.

\section{Result and Discussion}

The experiments were statistically planned using Taguchi's robust DOE methodology. The L9 orthogonal array was identified as one of the potential solutions for designing the experiments. The input parameters and their levels considered for the investigation are shown in Figure 4. The experimental readings recorded after experimentation are given in Table 2.

The variation in tensile strength of the welded joints is shown in Figure 5. The tensile strength of the weld has increased gradually with the increase in welding current. The maximum tensile strength is obtained at a welding current of $150 \mathrm{~A}$. An increase in tensile strength from 111.3 MPa to $184 \mathrm{MPa}$ is noted when the welding current increases from $130 \mathrm{~A}$ to $140 \mathrm{~A}$. It is an increase of $39.5 \%$ when considering the tensile strength at $130 \mathrm{~A}$. The tensile strength increases again from $184 \mathrm{MPa}$ to $198.3 \mathrm{MPa}$ with a further increase of welding current from $140 \mathrm{~A}$ to $150 \mathrm{MPa}$. The increase in tensile strength is $7.2 \%$ higher than that of tensile strength at $140 \mathrm{~A}$. This increase in tensile strength is due to the penetration of a large amount of heat at the interface. The increased amount of heat produced at the weld interface leads 


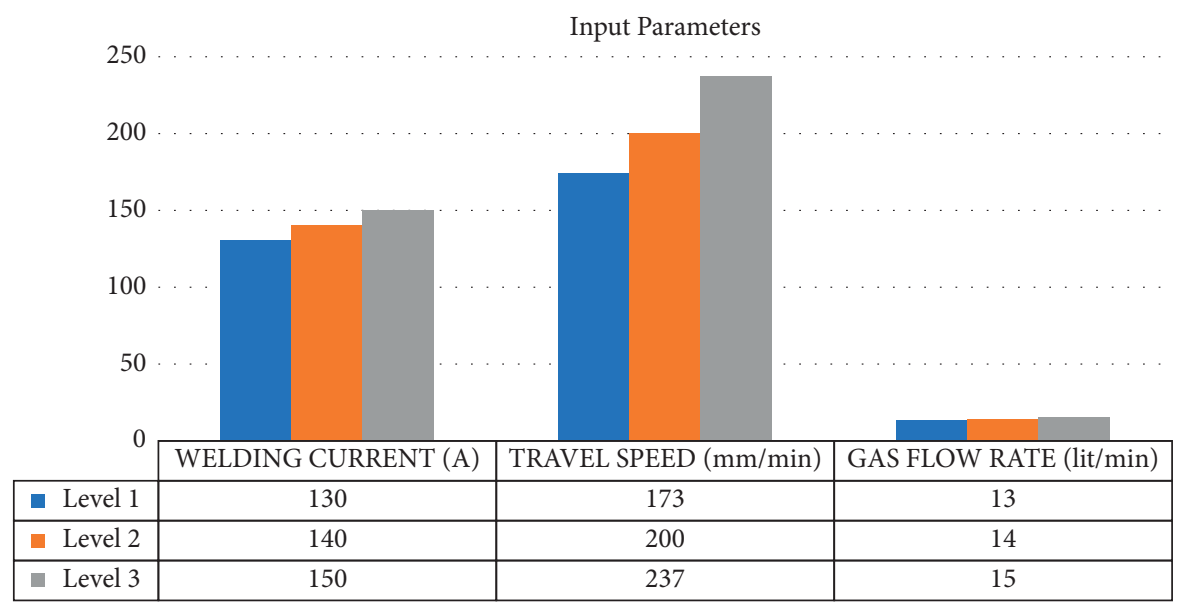

Figure 4: Parameters under consideration.

TABLE 2: Experimental results.

\begin{tabular}{lcccc}
\hline Welding current $(\mathrm{A})$ & Travel speed $(\mathrm{mm} / \mathrm{min})$ & Gas flow rate $(\mathrm{lit} / \mathrm{min})$ & Tensile strength $(\mathrm{MPa})$ & Hardness $(\mathrm{HV})$ \\
\hline 130 & 237 & 13 & 108 & 94 \\
130 & 200 & 14 & 132 & 86.5 \\
130 & 173 & 15 & 203 & 73.5 \\
140 & 237 & 14 & 200 & 65 \\
140 & 200 & 15 & 150 & 73.5 \\
140 & 173 & 13 & 193 & 72 \\
150 & 237 & 15 & 194 & 70 \\
150 & 200 & 13 & 208 & 56.9 \\
150 & 173 & 14 & & \\
\hline
\end{tabular}

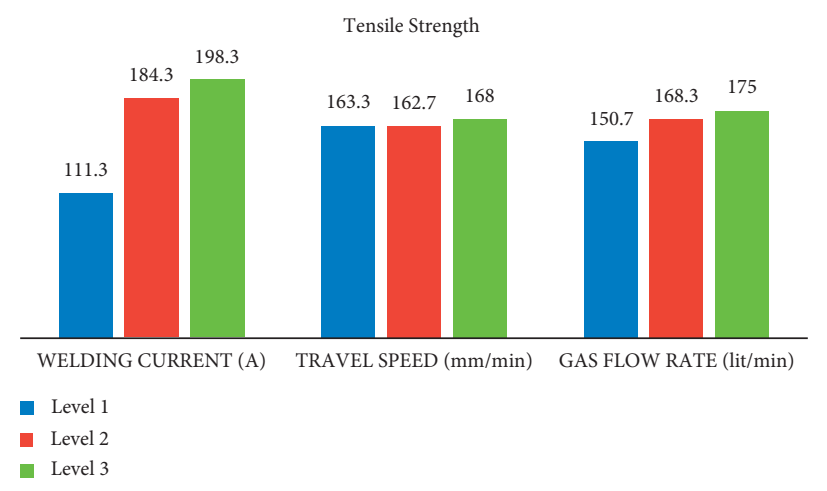

Figure 5: Effect of welding parameters over tensile strength.

to the increase of tensile strength of the welded joint. Eventhough the tensile strength of the welded joined has increased gradually with an increase in welding current, the travel speed of the filler has reduced the tensile strength to $200 \mathrm{~mm} / \mathrm{min}$ and increased beyond it. An increase in travel speed from $173 \mathrm{~mm} / \mathrm{min}$ to $200 \mathrm{~mm} / \mathrm{min}$ has reduced the tensile strength from 163.3 $\mathrm{MPa}$ to $162.7 \mathrm{MPa}$.

Furthermore, the tensile strength has increased from 162.7 $\mathrm{MPa}$ to $168 \mathrm{MPa}$, increasing travel speed from $200 \mathrm{~mm} / \mathrm{min}$ to $237 \mathrm{~mm} / \mathrm{min}$. The decrease in tensile strength when increasing the travel speed from $173 \mathrm{~mm} / \mathrm{min}$ to $200 \mathrm{~mm} / \mathrm{min}$ is $0.37 \%$, and an increase of $3.15 \%$ is seen when the travel speed is increased from $200 \mathrm{~mm} / \mathrm{min}$ to
$237 \mathrm{~mm} / \mathrm{min}$. Similarly, when the gas flow rate increases from $13 \mathrm{lit} / \mathrm{min}$ to $14 \mathrm{lit} / \mathrm{min}$, the tensile strength has increased from $150.7 \mathrm{MPa}$ to $168.3 \mathrm{MPa}$. This increase in tensile strength up to $10.46 \%$ is due to an increased supply of gas, facilitating the application of a higher amount of heat at the interface. This increased supply of heat at the interface resulted in better penetration of heat into the material. An increase of gas flow rate from $14 \mathrm{lit} / \mathrm{min}$ to 15 lit $\mathrm{min}$ has increased the tensile strength by $3.83 \%(168.3-175 \mathrm{MPa})$.

The hardness of the weld has decreased gradually with the increase in welding current. The maximum hardness is obtained at a welding current of $130 \mathrm{~A}$. Hardness increases from $73.33 \mathrm{HV}$ to $69.17 \mathrm{HV}$ when the welding current 


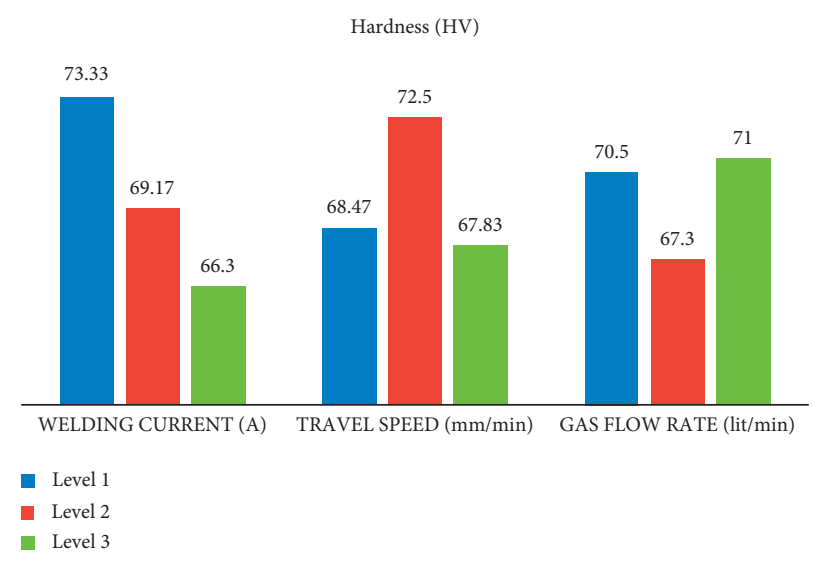

FIGURE 6: Effect of welding parameters over hardness.

TABLE 3: GRG for samples.

\begin{tabular}{|c|c|c|c|c|c|c|c|}
\hline S. no. & Normalized TS & Normalized HV & Del TS & Del HV & GRC TS & GRC HV & GRG \\
\hline 1 & 0.122807 & 0.415584 & 0.877193 & 0.584416 & 0.363057 & 0.461078 & 0.412068 \\
\hline 2 & 0 & 1 & 1 & 0 & 0.333333 & 1 & 0.666667 \\
\hline 3 & 0.333333 & 0.718615 & 0.666667 & 0.281385 & 0.428571 & 0.639889 & 0.53423 \\
\hline 4 & 0.95614 & 0.350649 & 0.04386 & 0.649351 & 0.919355 & 0.435028 & 0.677192 \\
\hline 5 & 0.929825 & 0.458874 & 0.070175 & 0.541126 & 0.876923 & 0.480249 & 0.678586 \\
\hline 6 & 0.491228 & 0.78355 & 0.508772 & 0.21645 & 0.495652 & 0.697885 & 0.596769 \\
\hline 7 & 0.868421 & 0.65368 & 0.131579 & 0.34632 & 0.791667 & 0.590793 & 0.69123 \\
\hline 8 & 0.877193 & 0.5671 & 0.122807 & 0.4329 & 0.802817 & 0.535963 & 0.66939 \\
\hline 9 & 1 & 0 & 0 & 1 & 1 & 0.333333 & 0.666667 \\
\hline
\end{tabular}

increases from $130 \mathrm{~A}$ to $140 \mathrm{~A}$. It is a decrease of $6 \%$ when considering the tensile strength at $130 \mathrm{~A}$. The hardness decreases again from $69.17 \mathrm{HV}$ to $66.3 \mathrm{HV}$ with a further increase of welding current from $140 \mathrm{~A}$ to $150 \mathrm{MPa}$. The decrease in hardness is $4.33 \%$ lower than that of tensile strength at $140 \mathrm{~A}$. This decrease in hardness is due to the poor solidification of the molten material. Eventhough there is a decrease in hardness of the welded joints with an increase in welding current, the travel speed of the filler has increased the hardness to $200 \mathrm{~mm} / \mathrm{min}$ and decreases beyond it. An increase in travel speed from $173 \mathrm{~mm} / \mathrm{min}$ to $200 \mathrm{~mm} / \mathrm{min}$ has increased the hardness from $68.47 \mathrm{HV}$ to $72.5 \mathrm{HV}$.

Furthermore, the hardness has decreased from $72.5 \mathrm{HV}$ to $67.83 \mathrm{HV}$ with an increase of travel speed from $200 \mathrm{~mm} /$ $\min$ to $237 \mathrm{~mm} / \mathrm{min}$. The increase in hardness when increasing the travel speed from $173 \mathrm{~mm} / \mathrm{min}$ to $200 \mathrm{~mm} / \mathrm{min}$ is $5.56 \%$, and a decrease of $6.88 \%$ is seen when the travel speed increased from $200 \mathrm{~mm} / \mathrm{min}$ to $237 \mathrm{~mm} / \mathrm{min}$. Similarly, when the gas flow rate increases from $13 \mathrm{lit} / \mathrm{min}$ to $14 \mathrm{lit} / \mathrm{min}$, the hardness decreases from $70.5 \mathrm{HV}$ to $67.3 \mathrm{HV}$. This decrease in hardness up to $4.75 \%$ is due to the increased supply of gas that has facilitated the application of the higher amount of heat at the interface resulting in poor solidification of the metal. An increase of gas flow rate from 14 lit/ min to 15 lit $\min$ has increased the hardness by $5.21 \%$ $(67.3-71 \mathrm{HV})$. Figure 6 shows the variation in hardness of the welded joints at varying levels of the considered parameters of investigation.
Grey relational analysis is used for multicriterion optimization because the contribution variables significantly impact the outcomes. All responses need to be maximized; thus, the more significant, the better equation is chosen for normalizing. Just after data were processed, the standardized data were recorded. GRC for independent output characteristics is approximated after assessing the variation sequence. Weightage is applied to individual outputs to determine the weighted GRG depending on the circumstances. Following the computation of GRC, the weighted GRG is computed. The responses are weighted based on the significance of the performance requirements. GRG for all the samples is given in Table 3.

Here, in this work, both the responses are given an equal weightage of $50 \%$ each. The appropriate operating conditions for joining AA6082 alloy are $150 \mathrm{~A}$ (higher level) of welding current, $200 \mathrm{~mm} / \mathrm{min}$ (medium level) of travel speed, and $14 \mathrm{lit} / \mathrm{min}$ (medium level) of gas flow rate, as shown in Figure 7. The interaction plot for the GRG is shown in Figure 8. The welding current and travel speed have a more significant relationship at a welding current of $13 \mathrm{~A}$. Also, the welding current interacts with the gas flow rate at the midlevel $(130 \mathrm{~A})$. Similarly, the travel speed interacts with welding current and gas flow rate at a higher level of $237 \mathrm{~mm} / \mathrm{min}$. When considering the relationship between the gas flow rate and the other two parameters, an interrelationship is identified at 14 lit/ min (midlevel). ANOVA analysis (Table 4) shows that the 


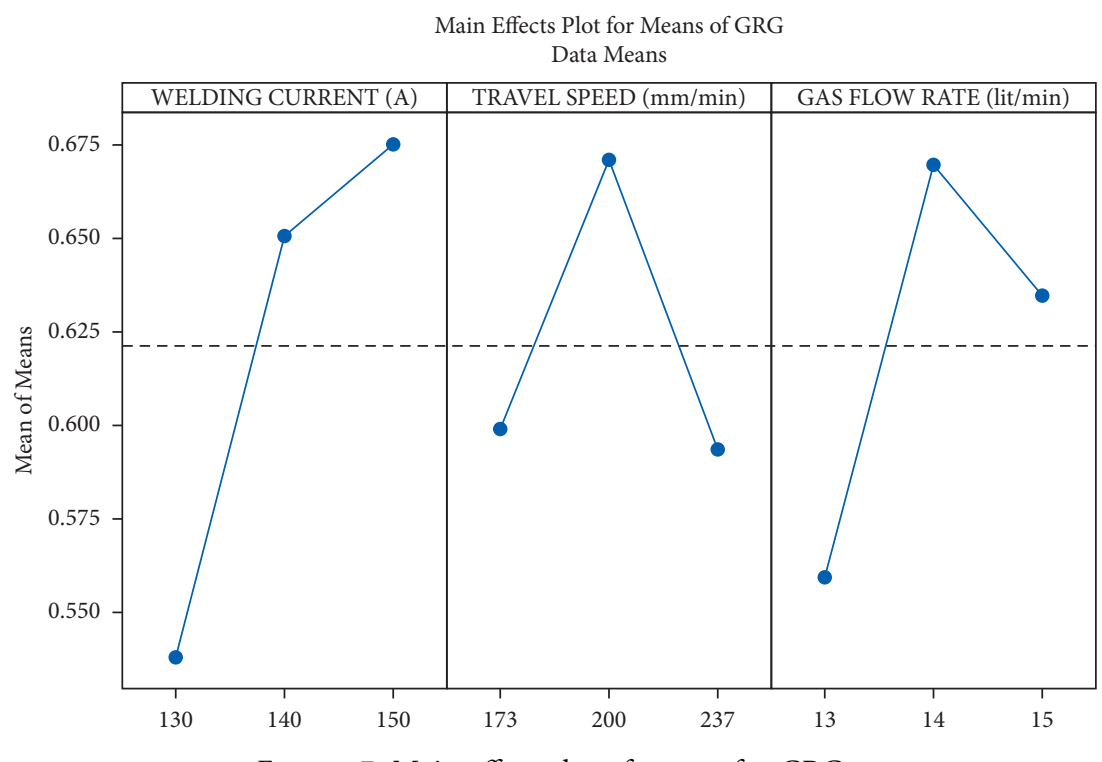

FIgURE 7: Main effect plot of means for GRG.

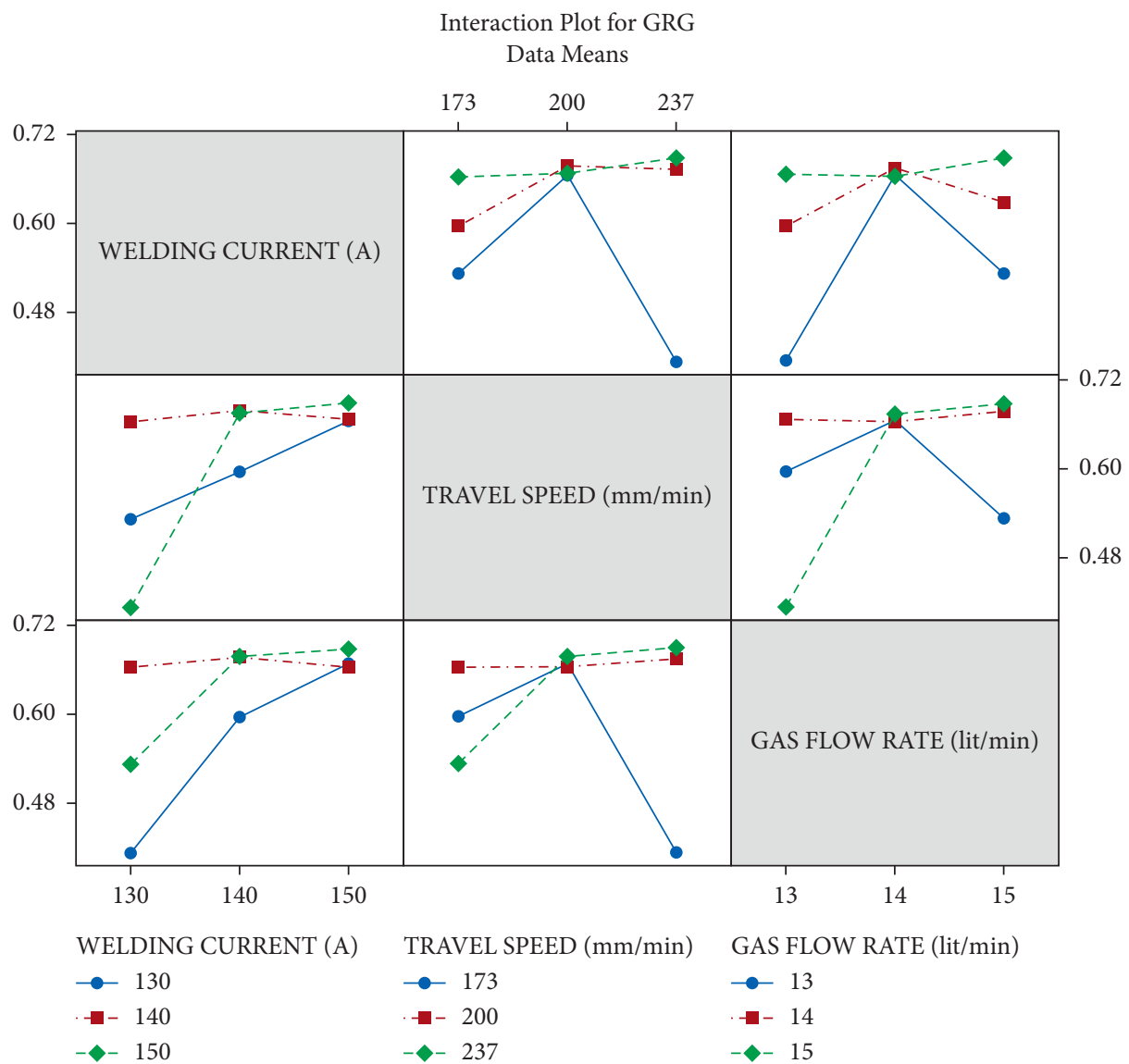

FIgUre 8: Interaction plot for GRG.

welding current has been the most influential parameter with a contribution of $46.65 \%$. The secondary controlling parameter is the gas flow rate with a contribution of $27.54 \%$, and the travel speed makes the minor contribution with $16.30 \%$. The validation experiments showed that the tensile strength for the optimized combination of parameters is $201.2 \mathrm{MPa}$ and is $18.16 \%$ higher than the mean of tensile strength obtained through experimentation. Similarly, the hardness for the optimized combination of parameters is $66.14 \mathrm{HV}$ and is $4.97 \%$ lower than 
TABLE 4: ANOVA for GRG.

\begin{tabular}{|c|c|c|c|c|c|c|c|}
\hline Source & $\mathrm{DF}$ & Seq SS & Adj SS & Adj MS & $F$ & $P$ & $\%$ contribution \\
\hline Welding current (A) & 2 & 0.032507 & 0.032507 & 0.016254 & 4.9 & 0.169 & 46.65 \\
\hline Travel speed $(\mathrm{mm} / \mathrm{min})$ & 2 & 0.011356 & 0.011356 & 0.005678 & 1.71 & 0.369 & 16.30 \\
\hline Gas flow rate (lit/min) & 2 & 0.019195 & 0.019195 & 0.009597 & 2.9 & 0.257 & 27.54 \\
\hline Residual error & 2 & 0.006628 & 0.006628 & 0.003314 & & & 9.51 \\
\hline Total & 8 & 0.069686 & 0.069686 & & & & \\
\hline
\end{tabular}

TABle 5: Response table for GRG.

\begin{tabular}{lccc}
\hline & Welding current $(\mathrm{A})$ & Travel speed $(\mathrm{mm} / \mathrm{min})$ & Gas flow rate $($ lit/min) \\
\hline 1 & 0.5377 & 0.5992 & 0.5594 \\
2 & 0.6508 & 0.6715 & 0.6702 \\
3 & 0.6758 & 0.5935 & 0.6347 \\
Delta & 0.1381 & 0.0781 & 0.1108 \\
Rank & 1 & 3 & 2 \\
\hline
\end{tabular}

the mean of hardness values obtained through experimentation. Table 5 provides that welding current has controlled GRG to a significant extend.

\section{Conclusion}

An experimental investigation on AA6082 alloy was conducted using the TIG welding process with Taguchi's L9 array. The findings of the investigation are provided. The tensile strength of the welded joint has increased by $43.87 \%$, with an increase in welding current due to the increased amount of heat produced at the weld interface and better penetration of heat into the metal across the material. Meanwhile, the hardness decreases by $10.60 \%$ when the welding current is increased. The tensile strength of the welded joint has increased by $2.80 \%$, whereas the hardness has decreased by $0.94 \%$ when the travel speed is increased. Similarly, tensile strength of the welded joint has increased by $13.94 \%$, whereas the hardness has increased by $0.7 \%$ when the gas flow rate is increased. According to GRA, the appropriate operating conditions for joining AA6082 alloy are $150 \mathrm{~A}$ (higher level) welding current, $200 \mathrm{~mm} / \mathrm{min}$ (medium level) travel speed, and $14 \mathrm{lit} / \mathrm{min}$ (medium level) gas flow rate. The welding current was the most influential parameter, accounting for $46.65 \%$ of the total, while travel speed was the least influential. The validation experiments revealed that the tensile strength for the optimized combination of parameters is $201.2 \mathrm{MPa}$, which is $18.16 \%$ greater than the experimental mean. Similarly, the optimized combination of parameters has a hardness of $66.14 \mathrm{HV}, 4.97 \%$ lower than the mean of hardness values obtained through experimentation.

\section{Data Availability}

The data used to support the findings of this study are included within the article and are available from the corresponding author upon request.

\section{Disclosure}

This study was performed as a part of the Employment Mettu University, Ethiopia.

\section{Conflicts of Interest}

The authors declare that there are no conflicts of interest.

\section{Acknowledgments}

The authors thank to Management of K. Ramakrishnan College of Technology and K. Ramakrishnan College of Engineering for their appreciation and encouragement to complete this research work with in-house research facilities.

\section{References}

[1] M. Samiuddin, J. L. Li, M. Taimoor, M. N. Siddiqui, S. U. Siddiqui, and J.-t. Xiong, "Investigation on the process parameters of TIG-welded aluminum alloy through mechanical and microstructural characterization," Defence Technology, vol. 17, no. 4, pp. 1234-1248, 2021.

[2] M. Muzamil, J. Wu, M. Samiuddin, A. Majeed, S. Uddin Siddiqui, and M. Mudassir, "Macro-mechanical behavior of unique surface welded joints (AA5083) utilizing tungsten inert gas welding against single-stage homogenization annealing," Revista de Metalurgia, vol. 56, no. 3, p. e173, 2020.

[3] L. Kaba, M. E. Djeghlal, S. Ouallam, and S. Kahla, "Dissimilar welding of aluminum alloys 2024 T3 and 7075 T6 by TIG process with double tungsten electrodes," International Journal of Advanced Manufacturing Technology, vol. 118, pp. 937-948, 2021.

[4] A. Kumar and S. Sundarrajan, "Effect of welding parameters on mechanical properties and optimization of pulsed TIG welding of Al-Mg-Si alloy," International Journal of Advanced Manufacturing Technology, vol. 42, no. 1-2, pp. 118-125, 2009.

[5] S. Baskutis, J. Baskutiene, R. Bendikiene, and A. Ciuplys, "Effect of weld parameters on mechanical properties and tensile behavior of tungsten inert gas welded AW6082-T6 aluminium alloy," Journal of Mechanical Science and Technology, vol. 33, no. 2, pp. 765-772, 2019. 
[6] N. Murali and X. Li, "TIG welding of dissimilar high-strength aluminum alloys 6061 and 7075 with nano-treated filler wires," in Light Metals 2021. The Minerals, Metals \& Materials Series, L. Perander, Ed., Springer, Berlin, Germany, 2021.

[7] T. Sathish, S. Tharmalingam, V. Mohanavel et al., "Weldability investigation and optimization of process variables for TIG-welded aluminium alloy (AA 8006)," Advances in Materials Science and Engineering, vol. 2021, Article ID 2816338, 17 pages, 2021.

[8] T. Rajkumar, K. Raja, K. Lingadurai, S. D. Vetrivel, and A. G. Antony, "Interfacial microstructure analysis of AA2024 welded joints by friction stir welding," Journal of New Materials for Electrochemical Systems, vol. 23, no. 2, pp. 123-132, 2020.

[9] T. Rajkumar, M. P. Prabakara, G. Arunkumar, and A. GodwinAntony, "Study on the feasibility in welding of low carbon steel and austenitic stainless steel joint using CO2 laser welding process and analysis of its metallurgical and mechanical properties," Wu Tan Hua Tan Ji Suan Ji Shu, vol. 106, no. 5, pp. 471-476, 2020.

[10] S. K. Singh, B. K. Samal, S. R. Pradhan, S. R. Ojha, M. D. Saffin, and A. M. Mohanty, "Sustainable analysis of tig parameters for welding aluminum alloy considering joint gap and welding current," Learning and Analytics in Intelligent Systems, vol. 5, pp. 316-323, 2020.

[11] A. K. Srirangan and S. Paulraj, "Multi-response optimization of process parameters for TIG welding of Incoloy $800 \mathrm{HT}$ by Taguchi grey relational analysis," Engineering Science and Technology, an International Journal, vol. 19, no. 2, pp. 811817, 2016.

[12] R. Devanathan, S. Arul, T. Venkatamuni, D. Yuvarajan, and D. C. Selvam, "The effect of sub-zero treatment on mechanical properties of gtaw welded AA6082," Applied Mechanics and Materials, vol. 852, pp. 349-354, 2016.

[13] A. Baskutis, J. Baskutiene, and E. Bernotaitis, "Experimental study of welded joints of aluminium alloy AW6082," Solid State Phenomena, vol. 260, pp. 212-218, 2017.

[14] A. Sivanantham, S. Manivannan, and S. P. K. Babu, "Parametric optimization of dissimilar TIG welding of AISI 304L and 430 steel using Taguchi analysis," in Materials Science Forum, pp. 625-630, Trans Tech Publications Ltd.,, Freienbach, Switzerland, 2019.

[15] A. Daniel Das, "Effect of TIG welding parameters on mechanical properties of Al6063 welded samples," Journal of Advanced Research in Dynamical and Control Systems, vol. 11, no. 12, pp. 1119-1125, 2019.

[16] P. K. Miniappan, V. V. Arun Shankar, and A. Saiyath Ibrahim, "An evaluation of microstructural effect on welding interface of welded samples," Bibliomed, vol. 7, no. 9, pp. 206-209, 2020.

[17] K. Hoyingchareon and P. Muangjunburee, "Welding repair of aluminium alloy 6082 T6 by TIG welding process," Materials Science Forum, vol. 872, pp. 3-7, 2016.

[18] D. Nathan, S. Ashwin Kannan, and P. Krishna Kumar, "Feasibility study of TIG welding of aa6063-aa7075 alloys," in Trends in Manufacturing and Engineering Management. Lecture Notes in Mechanical Engineering, S. Vijayan, N. Subramanian, and K. Sankaranarayanasamy, Eds., Springer, Berlin, Germnay, 2021.

[19] P. K. Jayashree, S. S. Sharma, R. Shetty, A. Mahato, and M. C. Gowrishankar, "Optimization of TIG welding parameters for 6061Al alloy using Taguchi's design of experiments," Materials Today Proceedings, vol. 5, no. 11, pp. 23648-23655, 2018.
[20] H. Zhong, B. Qi, B. Cong, Z. Qi, and H. Sun, "Microstructure and mechanical properties of wire + arc additively manufactured 2050 Al-Li alloy wall deposits," Chinese Journal of Mechanical Engineering, vol. 32, no. 1, p. 92, 2019.

[21] D. Varshney and K. Kumar, "Application and use of different aluminium alloys with respect to workability, strength and welding parameter optimization," Ain Shams Engineering Journal, vol. 12, no. 1, pp. 1143-1152, 2021.

[22] P. Omoniyi, M. Mahamood, T. C. Jen, and E. Akinlabi, "TIG welding of Ti6Al4V alloy: microstructure, fractography, tensile and microhardness data," Data in Brief, vol. 38, Article ID 107274, 2021. 